\title{
Prevenção às drogas nas escolas: uma experiência pensada a partir dos modelos de atenção em saúde
}

\author{
Drug prevention in the school environment: an experience \\ considered through the use of health care models
}

\author{
Ana Cláudia MÜLLER \\ Cátia Lucila PAUL ${ }^{2}$ \\ Nair Iracema Silveira dos SANTOS ${ }^{3}$
}

\begin{abstract}
Resumo
Ao longo da história da saúde pública, vários modelos de atenção foram construídos para orientar ações nessa área, destacandose o modelo biomédico, o da medicina comunitária e o em defesa da vida. Este artigo trata da análise de um projeto de prevenção às drogas no ambiente escolar realizado em Santa Maria (RS) e discute a relação desta proposta com os modelos de atenção em saúde. A partir da experiência, conclui-se ser necessário romper com o paradigma hegemônico e estruturar as ações de prevenção às drogas conforme modelos alternativos, permitindo que alunos, professores e comunidade assumam o papel de promotores de sua própria saúde.
\end{abstract}

Unitermos: Abuso de drogas. Política de saúde. Prevenção.

\begin{abstract}
Throughout the history of the public health system, several care models have been constructed to guide actions in this field, with particular emphasis on the biomedical model, the community medicine model and the "in defense of life" model. This article deals with the analysis of a drug prevention project in the school environment, conducted in Santa Maria (Rio Grande do Sul), and discusses the relationship of this proposal with the models of health care. From this experiment, we were able to observe that it is necessary to break with the hegemonic paradigm and to structure drug prevention activity in accordance with alternative models, thereby permitting students, teachers and community to partake on the role of promoters of their own health.
\end{abstract}

Uniterms: Drug abuse. Health care policy. Prevention.

Os serviços de saúde do Brasil e de outros países têm sido orientados por diferentes paradigmas ao longo da história, e as ações nesse campo têm se desenvolvido de acordo com diversos modelos de atenção. Dentre estes, destacam-se o modelo hegemônico - também denominado biomédico ou de medicina científica - e os modelos alternativos, tais como o da medicina comunitária e o em defesa da vida (Silva Júnior, 1998).

\section{$\operatorname{trat}$}

- Clínica Valéria Colomé. Santa Maria, RS, Brasil.

2 Prefeitura Municipal. Bom Retiro do Sul, RS, Brasil.

3 Universidade Federal do Rio Grande do Sul, Instituto de Psicologia, Programa de Pós-Graduação em Psicologia Social e Institucional. R. Ramiro Barcelos, 2600, Santa Cecília, 90035-003, Porto Alegre, RS, Brasil. Correspondência para/Correspondence to: N.IS. SANTOS. E-mail: <niss@terra.com.br>. 
A psicologia também tem acompanhado esse processo de remodelação da atenção à saúde. No presente artigo, propõe-se o debate de uma experiência de intervenção preventiva, problematizando-a a partir dos modelos tecnoassistenciais empregados nesse campo. Tal experiência foi realizada em uma escola pública de Santa Maria (RS), no ano de 2002, abordando o tema drogas com alunos de duas turmas de $5^{\text {a }}$ série.

Inicialmente, apresenta-se uma síntese sobre os modelos de atenção em saúde e seus princípios, assim como algumas referências acerca da prevenção às drogas nas escolas; em seguida, faz-se uma descrição das atividades realizadas no projeto de extensão e discute-se a relação da proposta de intervenção com os modelos tecnoassistenciais.

\section{Os modelos de atenção em saúde}

Os modelos de atenção em saúde são definidos pela organização do serviço a partir de arranjos de saberes da área e da construção de ações sociais específicas. Ou seja, eles se organizam conforme a tecnologia utilizada na assistência, o contexto social, econômico e político em que se inserem (Franco \& Merhy, 2004).

Como menciona Silva Júnior (1998), o modelo hegemônico da medicina científica - também chamado de Flexneriano - tem sua gênese histórica a partir das descobertas de Pasteur e Koch no ramo da biologia nos séculos XVIII e XIX, as quais provocaram o redimensionamento das funções das instituições hospitalares: de lugares de morredouro passaram a ser locais de trabalho da medicina científica. Esse modelo também foi impulsionado a partir do Relatório Flexner, organizado em 1910, no qual Abraham Flexner reavaliou a educação médica, o que resultou em grandes mudanças nessa área, tais como: a introdução do ensino laboratorial; a expansão do ensino clínico, principalmente em hospitais; a ênfase dada à pesquisa biológica e a especialização profissional.

O modelo hegemônico foi estruturado a partir de alguns princípios norteadores, destacando-se entre eles: o biologismo, o mecanicismo (corpo visto como uma máquina), individualismo (sujeitos e suas histórias tidos como alienados de seus aspectos sociais, psíquicos e políticos; causas das doenças consideradas como 608 exclusivas das práticas de cada sujeito) e a dicotomia mente-corpo. Além desses, outros elementos estruturais também se salientaram: a exclusão das práticas alternativas, a tecnificação do ato médico, a ênfase na medicina curativa, a concentração de recursos - os equipamentos e os serviços especializados restringiam-se a determinados espaços físicos, especialmente em hospitais das cidades mais populosas (Silva Júnior, 1998). Esse modelo de atenção focou-se na questão da doença e não explorou a prevenção, as potencialidades e possibilidades de saúde dos sujeitos. Enfim, foram utilizadas intervenções exclusivamente técnicas como forma de alcançar a cura.

A ineficiência, ineficácia e desigualdades na distribuição de seus progressos levaram a medicina científica a uma crise (Silva Júnior, 1998). Os resultados esperados na melhoria da saúde da população - como a redução nas taxas de mortalidade geral populacional e a melhora na expectativa e qualidade de vida - não foram proporcionais aos altos investimentos em serviços e profissionais.

Em conseqüência às críticas impostas ao modelo anterior, a partir da década de 40 surgiram outros modelos, dentre os quais se destaca o da medicina comunitária, que se orientou a partir da medicina simplificada enfatizando os cuidados primários em saúde, os programas de extensão de cobertura urbana e rural, assim como o incentivo à adesão e participação popular no planejamento em saúde. Esse modelo foi impulsionado por dois movimentos: o primeiro marcou a reestruturação dos serviços de saúde ingleses baseada em reflexões do médico Bertrand Dawson que, em 1920, propôs princípios distintos ao modelo flexneriano; o segundo, que ocorreu em 1978, foi a Conferência Internacional de Alma Ata (URSS), na qual as propostas da medicina comunitária foram repensadas e passaram a ter novas bases (Silva Júnior, 1998).

O relatório feito por Dawson indicava o Estado como o controlador das políticas de saúde, responsabilizando os serviços sanitários pelas ações preventivas e terapêuticas, regionalização das estruturas, bem como pelo provimento de médicos generalistas que pudessem cuidar dos sujeitos e das comunidades (Franco \& Merhy, 2004). Na Conferência Internacional sobre os Cuidados Primários em Saúde, em Alma Ata (URSS), assinalaramse as grandes desigualdades sociais existentes entre os países e salientou-se a importância da promoção e 
proteção da saúde das populações para uma melhoria na qualidade de vida.

Após o desenvolvimento da medicina comunitária, outro modelo alternativo à medicina científica surgiu por volta da década de 80: o modelo nomeado em defesa da vida. Este se estruturou a partir de idéias e trabalhos de um grupo de profissionais de saúde do Laboratório de Planejamento e Administração em Saúde (Lapa), criado no Departamento de Medicina Preventiva da Universidade Estadual de Campinas (Unicamp), que também estava vinculado ao Movimento Sanitário Nacional. Silva Júnior (1998) caracteriza tal modelo tecnoassistencial pelos seguintes princípios: gestão democrática, saúde como direito de cidadania, serviço público de saúde voltado para a defesa da vida individual e coletiva.

Vários autores (Foucault, Guattari, Deleuze, Testa, Matus, Baremblit, entre outros) tiveram suas produções teóricas utilizadas na construção da caixa-de-ferramentas: recurso metodológico de caráter flexível e que melhor se adaptava à problematização, discussão e construção de intervenções em saúde, de acordo com os precursores do modelo em defesa da vida. Também se propôs repensar os conceitos de saúde, doença e clínica - sendo a última vista como uma forma complementar à epidemiologia, que visa preservar a vida e a autonomia dos pacientes. Sugeriu também a desospitalização, ou seja, a descentralização de algumas ações para a rede básica de saúde, que deveria estar amparada por estabelecimentos de outros níveis de assistência (Silva Júnior, 1998).

Campos (2003), nessa linha de pensamento, também menciona alguns modos de intervenção clínica em saúde. Ele diferencia a clínica oficial (a degradada) e a ampliada. A primeira desresponsabiliza-se pela integralidade da saúde do indivíduo, prioriza a enfermidade nos atendimentos e focaliza o fator biológico, escamoteando as dimensões subjetiva e social das pessoas. Já a clínica ampliada prioriza o sujeito, sua doença e o contexto no qual se insere, objetivando com isso:

superar a alienação e a fragmentação e o tecnicismo biologicista, centrando-se no eixo de reconstituição de vínculos entre Clínico de Referência e sua clientela. Superar a fragmentação entre a biologia, subjetividade e sociabilidade operando-se com Projetos Terapêuticos amplos, que explicitem objetivos e técnicas da ação profissional e que reconheçam um papel ativo para o ex-paciente, para o enfermo em luta e em defesa de sua saúde, em geral, interligada com a saúde de outros (Campos, 2003, p.63).

Pode-se observar que na história da psicologia ocorreu o mesmo processo de mudança de paradigmas e de modelos de atenção. A partir da regulamentação de sua profissão, o psicólogo passou a atuar em quatro áreas principais: clínica, escolar, industrial e ensino. Mas, nas últimas décadas, essas se ampliaram, impulsionando os profissionais pra outros campos de intervenção, entre eles, o de saúde coletiva e pública. Esse movimento exigiu a construção de novas formas de ação e a crítica aos paradigmas teóricos até então empregados.

De acordo com Dimenstein (1998), o atendimento à saúde caracterizava-se pela naturalização do modelo biomédico assistencial privatista, orientado para a obtenção de lucro do setor privado de prestação de serviços. No setor de saúde mental, no qual os primeiros psicólogos inseriram-se, a realidade não era diferente: a atuação era hospitalocêntrica e visava à mercantilização da loucura. Entretanto, nos anos 70 do século passado, alguns movimentos sociais deram início à construção de outros paradigmas de atenção à saúde. A saúde mental começou, então, um processo de transformação e crítica ao asilo e à instituição psiquiátrica clássica, que culminaria posteriormente na concretização de uma nova forma de assistência em psiquiatria que preconizava a desospitalização e o investimento em serviços extra-hospitalares.

Nesse mesmo período, ganhou força a Reforma Sanitária, movimento que integrou intelectuais progressistas e trabalhadores da saúde, universidades e centros acadêmicos e organizações da sociedade civil. Esse processo reformista alcançou seu auge em 1986 ano em que se realizou a VIII Conferência Nacional de Saúde - e em 1988, quando foi criado o Sistema Único de Saúde (SUS). Nas últimas quatro décadas, observou-se uma crescente expansão na contratação de psicólogos em instituições públicas de saúde. No entanto, de acordo com alguns autores, não têm sido constatadas grandes mudanças nos paradigmas que orientam as intervenções do campo de atuação de tais profissionais. Mejias (1984), Dimenstein (2000) e TraversoYépez (2001) afirmam que houve na psicologia uma concepção de indivíduo psicológico cuja subjetividade 
é individualizada, particularizada, singular e constituída pela história pessoal de cada um, visão esta ainda predominante na área. Tal concepção tem orientado a formação de novos profissionais nas instituições de graduação e, por conseqüência, a atuação dos psicólogos na saúde pública.

De acordo com pesquisas realizadas nos estados do Rio Grande do Norte (Dimenstein, 2001; Oliveira et al., 2004) e no Distrito Federal (Seidl \& Costa Júnior, 1999), observou-se que as intervenções dos psicólogos ainda estão pautadas no modelo clínico, em detrimento do modelo de atenção integral à saúde. Esse contexto decorre do fato de que:

O modelo clínico de atuação privada hegemônico entre os psicólogos - a psicoterapia individual de base psicanalítica - é geralmente transposto para o setor público, tanto para posto, centros e ambulatórios de saúde, independentemente dos objetivos dos mesmos e da população neles atendidas, tendo algumas conseqüências importantes, entre as quais destaco:

a) Conflito com as representações de pessoa, saúde e doença, corpo, próprias aos usuários das instituições públicas de saúde;

b) Baixa eficácia das terapêuticas e alto índice de abandono dos tratamentos;

c) Seleção e hierarquização da clientela;

d) Psicologização de problemas sociais"(Dimenstein, 2000, p.107).

\section{Prevenção às drogas na escola}

O diálogo interdisciplinar e intersetorial nas intervenções em saúde tem permitido atualmente a construção de novas perspectivas de atuação em diversas áreas, entre elas, a prevenção na adolescência. Dessa forma, destaca-se a importância de se trabalhar conjuntamente com a escola e a família (Jeolás \& Ferrari, 2003). quando surgiu a estratégia de diminuir o uso indevido de drogas, a Organização das Nações Unidas para a Educação, a Ciência e a Cultura (Unesco) passou a enfatizar a abordagem preventiva ao abuso de drogas, tendo a escola como o espaço principal para este processo, pois parte significativa da população passa por esta instituição. Neste caso, a Unesco enfatizou a abordagem preventiva como educação para a saúde (Moreira, Silveira \& Andreoli, 2006).

A noção de escola como promotora de saúde surge a partir da aplicação dos princípios da Carta de Otawa endossados pela OMS. Essas escolas promotoras de saúde abordam "a natureza integral da saúde, eqüidade de gênero, envolvimento de toda a comunidade escolar, processo decisório participativo, sustentabilidade, adaptação cultural e inclusão de medidas que ampliem habilidades cognitivas e sociais" (Moreira, Silveira \& Andreoli, 2006, p.811).

Soares e Jacobi (2000) destacam a importância da escola como local privilegiado para trabalhar prevenção às drogas pela possibilidade de acesso aos jovens e pela natureza educacional de seu trabalho. Ressaltam, ainda, o despreparo para trabalhar com as dificuldades sociais e com as transformações culturais. Para estes autores, as instituições educacionais devem se afastar de cânones inflexíveis e passar a ver estas questões como os alunos as percebem, adicionando as necessidades e a demanda que surge no cotidiano escolar às práticas preventivas. Nesse sentido, os professores têm sido alvo dos programas de qualificação para ações de educação preventiva na linha participativo-construtivista, em defesa da reflexão crítica e do envolvimento de todos os segmentos participantes das instituições educacionais - pais, comunidade, corpo docente e discente.

Moreira et al. (2006) salientam duas maneiras de enfrentar o uso e abuso de drogas: a primeira que estimula a proibição, pela diminuição da oferta, com informações que se caracterizam pelo apelo moral e produção de medos, persuadindo as pessoas à abstinência; a segunda é a redução de danos, com propostas como: oferecimento de alternativas, educação para a saúde e modificações das condições de ensino.

A utilização do discurso Não às Drogas, que enfatizava os distúrbios e o adoecimento, negligenciava o outro lado do uso de tais substâncias: o prazer que elas proporcionam aos jovens. De que adianta dizer Não e ficar de costas aos sentimentos dos adolescentes? O que fazer quando o narcotráfico cresce em proporções maiores que as campanhas? O que pode fazer a escola diante desse panorama? 
Aratangy (1998) refere que metodologias preventivas que se utilizam somente de uma abordagem mais racional, que enfatiza o saber científico dos efeitos químicos das drogas, ou uma metodologia moralista e de enfoque religioso sobre esse tema, que busca definir as drogas em termos de bem ou mal, também não obtêm resultados preventivos adequados. Do mesmo modo, palestras proferidas por ex-usuários podem ser contraproducentes, pois podem alimentar a sensação de onipotência, tão característica da fase da adolescência, e provocar nos alunos um sentimento de que é possível experimentar, fazer uso e sair facilmente da drogadição.

A mesma autora menciona que encontros pontuais com especialistas externos à escola ajudam a aplacar a ansiedade da instituição, eximindo-a muitas vezes de se comprometer com um projeto mais amplo e consistente. Essas intervenções podem ser úteis quando fazem parte de um planejamento maior, que contemple outras atividades de interesse dos estudantes e da escola.

Aratangy (1998) sugere que o caminho para a prevenção do consumo de drogas passa pela exploração das questões emocionais dos adolescentes, e isso se dá por meio da abertura de canais de comunicação e participação, com atividades alternativas e não avaliativas pela escola, tais como as artísticas e esportivas. Considera-se que, muito mais importante do que alardear sobre proibições, ou seja, utilizar o discurso Não às Drogas, é importante criar espaços em que os jovens possam vivenciar experiências significativas e compartilhá-las em grupo. Além disso, mostra-se imprescindível a organização de atividades que envolvam o jovem na comunidade, assim como abrir espaços para orientação aos pais, para que estes não se sintam tão despreparados para lidar com os desafios da adolescência.

Carlini-Cotrim (1998) refere uma forma de prevenção ancorada na perspectiva de redução dos danos associados ao uso de drogas. A autora apresenta dois argumentos utilizados por defensores de tal modelo. $\mathrm{O}$ primeiro sustenta que o discurso do "mundo livre de drogas" fere os princípios éticos e direitos civis, uma vez que ditar regras de uso e normas de comportamento, além de ser medida insuficiente para o problema de usuários dependentes, priva os sujeitos de seu livre arbítrio e da autonomia em suas escolhas.
O segundo argumento afirma que a postura de guerra às drogas é irrealista, pois sua erradicação em nossa sociedade seria inviável pelas dificuldades de financiamento e execução. As sociedades humanas, conforme Salles (1998), sempre conviveram com algum tipo de substância psicoativa e fizeram uso desta para modificar seu estado de ânimo, ter acesso a algum tipo de conhecimento, estimular ou evitar algum tipo de sofrimento. Entretanto, a sociedade fazia uso das drogas de forma restrita, em rituais ou cerimoniais religiosos. Como havia certo controle, não se observava tão freqüentemente casos de abuso e dependência. As ações preventivas baseadas na postura de redução de danos não visam resultar, obrigatoriamente, em rejeição a qualquer contato com drogas. Acredita-se, somente, que quanto mais realizado e consciente estiver, menores são as chances de o jovem se envolver patologicamente com drogas (Carlini-Cotrim, 1998, p.29).

Nessa perspectiva, há uma preocupação com a diminuição dos danos causados à saúde e ao bemestar daqueles que usam drogas, mas também com a educação daqueles sujeitos que consideram que a opção mais segura é não usá-las. Evidências epidemiológicas mostram que as drogas lícitas são causa de problemas tanto quanto as ilícitas, o que faz com que esse modelo alternativo de prevenção enfoque em especial o álcool e o fumo. Na prática, o modelo visa articular ações que envolvam o conhecimento científico, educação afetiva, oferecimento de alternativas, educação para a saúde e modificação das condições do sistema de ensino.

Os programas de prevenção do Ministério da Saúde (Bucher, 1995) têm se caracterizado pela mudança no discurso em relação às drogas. Até recentemente as campanhas ganhavam espaço na mídia enfatizando os danos causados na relação com as drogas, especialmente aquelas ilícitas. Na atualidade, os grandes chamamentos têm sido direcionados para a valorização da vida e para a expansão de atividades que favoreçam a melhoria da qualidade de vida, acompanhando as novas propostas de atenção à saúde e a problematização do conceito de saúde centrado na idéia de ausência de doença. Moreira et al. (2006) afirmam que as intervenções preventivas sobre as drogas mais prósperas são as que se ampliam para o espaço físico e social, dando ênfase à saúde como um todo e aproximando-se do conceito de promoção de saúde. A experiência relatada a seguir apóia-se nesta perspectiva. 


\section{Método}

A experiência da qual trata este artigo refere-se a um projeto de extensão universitária desenvolvido por acadêmicos do curso de Psicologia da Universidade Federal de Santa Maria, no ano de 2002. O projeto teve como principal objetivo abrir espaços de discussão na escola sobre um tema de grande relevância, principalmente quando se considera a realidade do município, com seus altos índices de consumo de drogas e o fato de ser alvo de organizações do tráfico, pela localização geográfica de referência para rota. Também não se pode esquecer que Santa Maria é um pólo educacional, com uma população significativa de jovens estudantes nos diversos níveis de ensino (Saldanha, 1999).

A proposta para tal intervenção surgiu a partir do pedido do corpo docente de uma escola pública da cidade, na expectativa da abordagem de um polêmico tema transversal proposto nos parâmetros curriculares nacionais: as drogas. Esta demanda surgiu em turmas de $5^{\text {as }}$ e $6^{\text {as }}$ séries, em uma aula de Português, quando a professora dessa disciplina fez o levantamento de temas sobre os quais os alunos tinham interesse. A surpresa e preocupação dos professores com tal escolha, e as dúvidas sobre como trabalhar com esta questão, direcionaram o pedido de apoio à universidade.

$\mathrm{O}$ projeto pode ser dividido em duas fases. $\mathrm{Na}$ primeira etapa, visando à familiarização com as turmas de $5^{\text {as }}$ séries escolhidas para se iniciar as atividades, realizou-se seis encontros com duas turmas em separado, reunindo-as em alguns momentos. Vários recursos foram empregados nesses encontros, tais como confecção de painéis contando a história da turma, utilizando para isso diversos materiais; representação de cenas sobre o cotidiano escolar em pequenos grupos; jogos de futebol e vôlei no pátio; perguntas distribuídas em dois encontros focando temas como drogas, família, escola e juventude. Os elementos utilizados tiveram como objetivo proporcionar integração entre os alunos, e destes com os acadêmicos, e criar um ambiente propício à expressão de idéias e sentimentos de uma forma dinâmica.

Ainda na primeira fase, procurou-se iniciar a discussão com a família e com os professores. Foi elaborado um anteprojeto para a análise com os segmentos

612 citados, visando à criação de um planejamento coletivo da escola. Os acadêmicos de psicologia e alguns professores da escola em questão participaram de encontros no Conselho Municipal de Entorpecentes (COMEN/SM), discutindo propostas de prevenção na escola.

Na reunião com os pais, explorou-se o que era pensado sobre as drogas, como essa questão era tratada em casa, quais as drogas conhecidas e o que achavam sobre a proposta do projeto de prevenção ao uso de tais substâncias. Apesar de um número reduzido, os pais e responsáveis presentes na reunião falaram de idéias, dúvidas, questionamentos e dificuldades com os filhos. Posteriormente, algumas mães participaram de visitas a setores da comunidade para entrevistas estas fizeram parte da segunda etapa do projeto de extensão. Com os professores, obteve-se a aprovação das idéias propostas, mas não se conseguiu que inserissem a discussão do tema nas respectivas disciplinas. Apenas a professora de Artes procurou desenvolver slogans para o projeto, aos quais só se teve acesso no final das atividades por conta das dificuldades de contato com o corpo docente.

Na segunda fase do projeto, a idéia construída e compartilhada com pais e professores consistia na elaboração de um documentário abordando o tema drogas. Para isso, houve a colaboração de uma professora do curso de Comunicação Social da Universidade Federal de Santa Maria (UFSM), que realizou uma exposição teórica sobre o que era um documentário e sugeriu outra definição para o que se daria conta nesse estágio do trabalho: um vídeo com uma edição curta.

Iniciou-se a elaboração do vídeo com a realização de entrevistas na própria comunidade - no posto de saúde, no bar, no posto da Brigada Militar e nas famílias -, objetivando com isso contextualizar o tema drogas de acordo com a realidade dos escolares. Em pequenos grupos, os alunos debateram acerca do tema e formularam perguntas a serem utilizadas nas entrevistas, o que os mobilizou bastante, permitindo a troca de idéias, experiências, curiosidades e medos. Algumas dessas entrevistas foram filmadas ou gravadas em áudio. Posteriormente, a partir dos temas discutidos, os mesmos grupos construíram cenas para dramatização, abordando diversas situações: a influência das drogas lícitas e ilícitas na família, na escola, entre os amigos, no namoro e no trabalho. Estas cenas foram gravadas em vídeo. 
Parte desse material foi aproveitada em uma edição amadora organizada para apresentação pelos próprios alunos nas atividades de encerramento do ano letivo na escola. Concomitantemente ao processo de filmagem das dramatizações, um grupo se organizou com atividades orientadas à composição e apresentação de músicas relacionadas ao assunto trabalhado. A organização deste grupo foi espontânea. As atividades propostas buscaram romper com posturas rígidas e preconceituosas, por meio de uma metodologia participativa e favorável às discussões.

Paralelamente à execução do projeto de extensão universitária na escola, os graduandos de psicologia criaram um espaço para discutir suas vivências, valores, pensamentos e implicações com o tema abordado nas salas de aula. Nesses momentos de reflexão crítica, algumas inquietações e questionamentos foram levantados: afinal, qual é o papel da psicologia na saúde? Quais as intervenções possíveis na área de saúde do escolar? Qual postura deve ser adotada diante de um tema tão polêmico? Como ir além de palestras, da simples (in)formação e da repressão moral? Que modelo de atenção à saúde adotar?

\section{Resultados e Discussão}

\section{Pensando a intervenção a partir dos modelos de atenção}

Analisando as discussões e as atividades de integração com os grupos de alunos, percebeu-se que no ambiente socioeconômico em que viviam a exposição às drogas lícitas era maior. As primeiras experiências com as bebidas alcoólicas e o fumo se davam em idade muito precoce e no seio familiar ou na comunidade. Muitos relatos indicaram que os alunos, familiares e até mesmo os professores, em algum momento, haviam feito uso de alguma droga lícita, o que tornava os participantes do projeto familiarizados com o tema trabalhado e portadores de uma bagagem de vivências diretas e indiretas com esse tema.

De posse dessas informações e conscientes de que as drogas permeavam o cotidiano dos adolescentes, os acadêmicos de psicologia questionaram-se sobre a perspectiva a partir da qual se deveria abordar esse assunto tão polêmico. A partir disso, constataram que adotar uma postura repressora e moralista, realizando tentativas de intimidação dos jovens, não seria o caminho mais adequado a seguir. Com isso, as riquíssimas experiências e vivências trazidas pelos adolescentes estariam sendo negligenciadas, criando obstáculos para um posicionamento mais autônomo por parte deles diante das discussões propostas, pois, como elucida Carlini-Cotrim (1998), as estratégias clássicas pecam por colocar os estudantes em uma posição heterônoma e proibitiva em relação à apropriação de seus pensamentos e exploração dos prazeres oriundos de seus corpos. Os acadêmicos procuraram não adotar a postura de especialistas, apesar da freqüente insistência da escola nesse sentido, mas sim de facilitadores das discussões e das ações.

O corpo docente da escola procurou, desde o início das atividades do projeto de extensão, responsabilizar somente os acadêmicos de psicologia pela realização das atividades de prevenção, pautado no modelo clássico de intervenção, em que a escola requisita ajuda colocando-se no lugar de não-saber e atribuindo poder a um especialista. No entanto, para os acadêmicos foi fundamental caracterizar o plano de ação não como da psicologia, mas da instituição escolar, permitindo que esta se apropriasse da proposta.

Buscou-se o rompimento com o modelo hegemônico, não somente pela quebra do princípio de que a cura se dá por meio do especialismo, como aponta Silva Júnior (1998), mas também rompendo com o pressuposto adotado por este paradigma, que afirma que o sujeito é o único responsável por suas práticas de saúde. Dimenstein (1998) comenta que muitas das intervenções dos psicólogos em saúde continuam permeadas por este pensamento, desconsiderando o contexto sócio-histórico em que os sujeitos estão inseridos. Amparado pelo modelo em defesa da vida, o projeto objetivou construir uma proposta em conjunto, tomando-se a realidade e o cotidiano dos sujeitos envolvidos como base para a elaboração das atividades, assim como a trajetória dos indivíduos, historicamente construída.

Para isso, criou-se nas turmas um espaço aberto à discussão e expressão de opiniões sem um juízo valorativo e moralista, o que permitiu que os alunos pudessem encarar as drogas e suas conseqüências não de uma forma idealizada, mas também não irreal, como 
acontece em muitos espaços abertos para tal, nos quais se procura enfatizar o discurso Não às Drogas sem ver seu lado reverso, que é o prazer proporcionado por tais substâncias. Como aponta Salles (1998), as drogas sempre estiveram presentes ao longo da história da humanidade e este fato não pode ser negligenciado; é preciso pensar em formas de não tornar esse uso tão nocivo, como ocorre atualmente.

O espaço aberto e franco criado entre acadêmicos, professores e alunos possibilitou que se transmitissem informações sobre as drogas conforme o interesse dos adolescentes. Estes puderam assimilar tais dados e mostrar como se expressam em seu cotidiano familiar e acadêmico; assim, puderam realizar trocas de forma contextualizada. Com o vídeo de curta duração, procurou-se colocar os alunos no lugar de autores, de modo a se apropriarem do tema abordado e mostrarem a ótica deles acerca do tema, como uma forma de expor o seu olhar sobre o contexto em que vivem e a relação deste com as drogas.

O projeto apoiou-se no paradigma estético proposto por Guattari (1993), uma alternativa ao modelo científico no universo capitalista: um paradigma de criatividade que abre para rupturas nas práticas naturalizadas e para a produção de outras subjetividades. Guattari (1993) insiste em um "caráter criacionista" no paradigma estético, que não significa "estetizar o mundo", mas sim criar um campo de experimentação e invenção de outros modos de existência. A experiência dos acadêmicos de psicologia com a escola implicou a composição de estratégias pautadas pela intensificação de brechas nos espaços fixos e lugares marcados nos quais professores e alunos pouco se movimentam no cotidiano escolar. Uma dimensão ética sustentou as ações e exigiu também uma análise permanente das ações dos pesquisadores e dos lugares ocupados nas relações estabelecidas com a escola, alunos, professores, saberes, drogas e práticas, problematizando os modos de produção de conhecimento e de promoção de saúde na escola. Procurou-se não psicologizar, nem pedagogizar, muito menos escolarizar o tema drogas na escola, adotando-se sempre uma postura transdisciplinar.

Com a utilização do paradigma estético como norteador das ações do projeto, buscou-se romper com o modelo tecnoassistencial hegemônico, visto que o 614 pedido da escola por uma intervenção pautada nesse último era evidente. A intervenção junto aos alunos orientou-se conforme o modelo em defesa da vida, uma vez que rompeu com a visão mecanicista e biologicista da perspectiva curativa da medicina científica. Visou construir, em conjunto com os adolescentes, novos modos de existência, processos de diferenciação e de singularização, tal como Campos (2003) afirma ser a função dos profissionais da área de saúde junto aos usuários dos serviços.

Experiências de prevenção mostram que propostas pontuais e isoladas não trazem os mesmo benefícios e resultados do que aquelas que se desenvolvem de forma continuada e abarcam os diversos setores do ambiente escolar (Aratangy, 1998). Entendeuse, portanto, que a prevenção deveria ser realizada em um programa que tivesse a adesão e implicação do corpo docente e de funcionários da escola, assim como da família e comunidade escolar. Por isso, os pais dos jovens foram convidados a participar da elaboração das entrevistas na comunidade e integrados à discussão que estava sendo realizada em sala-de-aula. O corpo de profissionais da escola, que não se restringiu somente aos professores, também se ocupou dos debates e questionamentos, não somente no ambiente escolar, mas também fora dele, por meio da participação em eventos no Conselho Municipal de Entorpecentes, nos quais se debateu sobre o papel das escolas na prevenção ao abuso de drogas. Os professores e familiares também são entendidos como agentes de prevenção, por isso a inserção deles nas discussões pertinentes a esta pesquisa foi imprescindível.

Ao longo do projeto, surgiu o desafio de pensar a relação entre a psicologia, a educação e a saúde. Historicamente, esta interface constituiu-se pela via do "especialismo", que colocou os profissionais da saúde, incluindo a psicologia, em lugares de saber e poder na relação com educadores, com intervenções centradas nos desvios, sintomas e patologias. A concepção de saúde que perpassa este tipo de relação vai de encontro às formulações da Reforma Sanitária e da construção do SUS. A escola solicitou uma intervenção baseada no modelo de relação construída entre esses campos, que tem operado com divisões conhecidas, tais como: aluno normal x aluno problema, família estruturada x família desestruturada, professor competente $x$ professor incompetente. Esse é um modelo sustentado no para- 
digma de ciência no qual a psicologia historicamente se ancorou, marcada por práticas individualizantes e produtoras dos próprios desvios para os quais é chamada a intervir. O pedido da escola à universidade foi formalizado em um contexto que transforma o interesse dos alunos pelo tema drogas em "problema" para a psicologia, sob expectativas de "mudanças de comportamento" em uma "turma difícil", conforme expressões de professores em reuniões com a equipe.

No trabalho desenvolvido na escola, procurouse não assumir um papel moralizador e doutrinador, tomando o conhecimento como algo estanque e acabado, mas possibilitaram-se experiências criativas, nas quais professores e alunos pudessem se colocar em outros lugares e papéis, compreendendo as forças que transversalizam a escola e tomando o fenômeno das drogas em seu contexto histórico-social. As ações foram pautadas não pensando em termos de desvios e doenças, mas considerando os sujeitos concretos, sociais e subjetivamente construídos. Com isso possibilitou-se, como afirma Foucault (1985), desterritorializar formas enraizadas de intervenção e reterritorializá-las a partir de outros modelos de atenção em saúde.

\section{Considerações Finais}

A partir do modelo de atenção em saúde proposto pelo projeto, atingiu-se o objetivo de intervir abrindo espaços para discussão do tema drogas na escola, respeitando o momento dos alunos, os interesses e trabalhando principalmente com a formulação de questões pelos grupos e com o desenvolvimento de atividades nas quais os estudantes pudessem agir de forma criativa e investigativa. A marca ética do grupo esteve presente na busca da ruptura com o modelo biomédico, que perpassa também algumas práticas da psicologia, procurando dar voz aos alunos e criando possibilidade de participação e de tomada de decisões, de modo que estes pudessem se colocar em outros lugares e territórios. O incentivo à participação dos sujeitos sociais no processo de produção de saúde, tal como foi feito neste projeto, assemelha-se ao proposto pelo modelo em defesa da vida.

Ao contrário da demanda da escola por ações pautadas pelo modelo biomédico, baseado na função curativa e orientado pelo especialismo, buscou-se focar a experiência de intervenção da psicologia em um modelo de saúde alternativo. Pode-se pensar que o paradigma estético utilizado nessa experiência tem seu paralelo no modelo em defesa da vida, que inclusive tem servido como base para os Parâmetros Curriculares Nacionais do Ministério da Educação e Cultura e para as ações em saúde escolar.

Considerando especificamente o espaço da psicologia em atividades de prevenção em saúde nas escolas ou em outras instituições, constatou-se ser fundamental desenvolver um pensamento crítico-reflexivo acerca dessas ações, não as tomando como naturalizadas e enraizadas.

Para obter resultados mais completos, seria necessário acompanhar esses adolescentes por um período maior, para perceber que implicações as intervenções do projeto alcançaram. A discussão apresentada neste artigo pode contribuir para a problematização de escolhas metodológicas e seus efeitos em abordagens de prevenção às drogas na escola.

\section{Referências}

Aratangy, L. R. (1998). O desafio da prevenção. In J. G. Aquino (Org.), Drogas na escola: alternativas teóricas e práticas. São Paulo: Summus Editorial.

Bucher, R. (1995). Prevenindo contra as drogas e DST/AIDS. Cartilha do Educador. Brasília: Ministério da Saúde.

Campos, G. W. (2003). Clínica ampliada e paidéia (pp.63-64). São Paulo: Hucitec.

Carlini-Cotrim, B. (1998). Drogas na escola: prevenção, tolerância e pluralidade. In J. G. Aquino (Org.), Drogas na escola: alternativas teóricas e práticas. São Paulo:Summus Editorial.

Dimenstein, M. D. B. (1998). O psicólogo em Unidades Básicas de Saúde: desafios para a formação e atuação profissionais. Estudos de Psicologia (Natal), 3 (1), 58-81.

Dimenstein, M. D. B. (2000). A cultura profissional do psicólogo e o ideário individualista: implicações para a prática no campo da assistência pública à saúde. Estudos de Psicologia (Natal), 5 (1), 95-121.

Dimenstein, M. D. B. (2001). O psicólogo e o compromisso social no contexto da saúde coletiva. Psicologia em Estudo, 6 (2), 57-63.

Foucault, M. (1985). História da sexualidade 3: o cuidado de si. Rio de Janeiro: Graal.

Franco, T. B., \& Merhy, E. E. (2004). Programa de Saúde da Família (PSF): contradições de um programa destinado à mudança do modelo tecnoassistencial. In E. E. Merhy (Org.), O trabalho em saúde: olhando e experienciando o SUS no cotidiano (pp.55-124). São Paulo: Hucitec. 
Guattari, F. (1993). Entrevistas: Guattari, o paradigma estético. Cadernos de Subjetividade, 1 (1), 29-34.

Jeolás, L. S., \& Ferrari, R. A. P. (2003). Oficinas de prevenção em um serviço de saúde para adolescentes: espaço de reflexão e conhecimento compartilhado. Ciência e Saúde Coletiva, 8 (2), 611-620

Ministério da Educação e Cultura (1998). Parâmetros Curriculares Nacionais. Brasília: MEC.

Mejias, N. P. (1984). O psicólogo, a saúde pública e o esforço preventivo. Revista de Saúde Pública, 18 (2), 155-161.

Moreira, F. G., Silveira, D. X., \& Andreoli, S. B. (2006). Redução de danos do uso indevido de drogas no contexto da escola promotora de saúde. Ciência e Saúde Coletiva, 11 (3), 807-816

Oliveira, I. F., Alvarenga, A. R., Carvalho, D. B., Costa, A. L. F., Dantas, C. M. B., Silva, F. L., et al. (2004). O psicólogo nas Unidades Básicas de Saúde: formação acadêmica e prática profissional. Interações: Estudos e Pesquisas em Psicologia, 9 (17), 71-89.

Saldanha, V. B. (1999). II Estudo epidemiológico sobre o uso de drogas psicotrópicas por estudantes do ensino fundamental, médio e superior de Santa Maria - RS. Santa Maria: UFSM.
Salles, L. M. F (1998). As drogas e o aluno adolescente. In J. G. Aquino (Org.), Drogas na escola: alternativas teóricas e práticas. São Paulo: Summus Editorial.

Seidl, E. M. F., \& Costa Júnior, A. L. (1999). O Psicólogo na Rede Pública de Saúde do Distrito Federal. Psicologia Teoria e Pesquisa (Brasília), 15 (1), 27-35. (1999).

Silva Jr, A. G. (1998). Modelos tecnoassistencias em saúde: o debate no campo da saúde coletiva. São Paulo: Hucitec.

Soares, C. B., \& Jacobi, P. R. (2000). Adolescentes, drogas e AIDS: avaliação de um programa de prevenção escolar. Cadernos de Pesquisa, (109), 213-237.

Traverso-Yépez, M. (2001). A interface psicologia social e saúde: perspectivas e desafios. Psicologia em Estudo, 6 (2), 49-56.

Recebido em: 27/7/2006

Versão final reapresentada em: 25/4/2007

Aprovado em: 15/8/2007 